Full-length article

\title{
Microinjection of resveratrol into rostral ventrolateral medulla decreases sympathetic vasomotor tone through nitric oxide and intracellular $\mathrm{Ca}^{2+}$ in anesthetized male rats ${ }^{1}$
}

\author{
Hui-juan MA, Ya-kun CAO, Yi-xian LIU, Ru WANG, Yu-ming WU² \\ Department of Physiology, Hebei Medical University, Shijiazhuang 050017, China
}

\section{Key words \\ resveratrol; renal sympathetic nerve activity; estrogen receptor; nitric oxide; $\mathrm{Ca}^{2+}$; protein tyrosine kinase \\ ${ }^{1}$ This work was supported by the National Natural Science Foundation of China (No 304005); New Century Excellent Talents Foundation of Ministry Enducation of China (No NCET-07-0252); the Natural Science Foundation of Hebei Province (№ 303467), the Science and Technology Department of Hebei Province (No 062761383), and The Administration of Traditional Chinese Medicine of Hebei Province (No 2006197). ${ }^{2}$ Correspondence to Prof Yu-ming WU. Phn/Fax 86-311-8626-6407. \\ E-mailwuym@hebmu.edu.cn}

Received 2007-12-27

Accepted 2008-05-19

doi: 10.1111/j.1745-7254.2008.00827.x

\begin{abstract}
Aim: To define the effect of resveratrol (RES) on the central regulation of blood pressure (BP), heart rate (HR), and renal sympathetic nerve activity (RSNA). Methods: RES was microinjected into the rostral ventrolateral medulla (RVLM), and BP, HR, and RSNA were recorded simultaneously in anesthetized rats. Results: A microinjection of RES (20, 40, and $80 \mu \mathrm{mol} / \mathrm{L}, 0.2 \mu \mathrm{L})$ into the RVLM dose dependently decreased BP, HR, and RSNA. Pretreatment with an anti-estrogen tamoxifen $(100 \mu \mathrm{mol} / \mathrm{L}, 0.2 \mu \mathrm{L})$ did not affect the effects of RES. Pretreatment with $N^{\mathrm{G}}$-nitro$L$-arginine methyl ester $(100 \mu \mathrm{mol} / \mathrm{L}, 0.2 \mu \mathrm{L})$, an inhibitor of nitric oxide (NO) synthase, could completely abolish the effect of RES. A prior microinjection of Bay K8644 ( $500 \mathrm{nmol} / \mathrm{L}, 0.2 \mu \mathrm{L})$, an agonist of calcium channels, could also abrogate the effect of RES. Prior administration of a potent inhibitor of tyrosine phosphatase, sodium orthovanadate $(1 \mathrm{mmol} / \mathrm{L}, 0.2 \mu \mathrm{L})$, could partially attenuate the inhibitory effect of RES. Conclusion: The results suggest that a microinjection of RES into the RVLM inhibits BP, HR, and RSNA. The effects may be mediated by $\mathrm{NO}$ synthesis and a decrease in $\mathrm{Ca}^{2+}$ influx, in which protein tyrosine kinase is involved.
\end{abstract}

\section{Introduction}

Resveratrol (3, 4',5-trihydroxystilbene; RES) is a naturally occurring phenolic substance present in a variety of plants, such as Polygonum cuspidatum roots, grapes and, red wine ${ }^{[1,}$ ${ }^{2]}$. It is also abundant in Chinese herbal medicines, including the cassia seed, hellebore, and giant knotweed rhizome ${ }^{[3]}$. RES has been reported to have a variety of estrogenic, antiinflammatory, antiplatelet, and anticarcinogenic effects ${ }^{[2,4,5]}$. Several recent studies showed the cardioprotective ability of RES ${ }^{[6]}$. Both in acute and in chronic models, RES protects the cardiovascular system against ischemic-reperfusion injury via locally released nitric oxide (NO) ${ }^{[7]}$, and it protects and maintains the intact endothelium and exhibits estrogenlike action ${ }^{[8]}$. Additionally, RES can induce vasorelaxation by inhibiting $\mathrm{Ca}^{2+}$ influx ${ }^{[9]}$. Moreover, RES is thought to be one of the main causes of the well known "French paradox", which refers to the French suffering low rates of heart dis- ease despite a diet relatively high in fat ${ }^{[10]}$. Thus RES may show potential clinical value in the treatment of cardiovascular disease as an alternative medicine.

It is generally accepted that the rostral ventrolateral medulla (RVLM) plays a pivotal role in the regulation of vascular tone and the maintenance of blood pressure (BP). The RVLM neurons have been shown to be involved in various sympathetic reflexes and the integration of the inputs from a variety of visceral, somatic, and supra medullary structures $^{[11,12]}$. It is a key region for the control of sympathetic drive to the periphery. The activity of RVLM neurons can dominate peripheral vascular tone and arterial BP. The RVLM is an important, possible link in the pathogenesis of hypertension, and in turn becomes a possible therapeutic target.

Previous studies have shown that RES has a beneficial effect on cardiovascular system via the peripheral mecha- 
nism $^{[6-8]}$. The direct effects of RES on the cardiovascular center have not yet been examined. The RVLM is a key region of the cardiovascular center. The purpose of this study was to ascertain the effect of a microinjection of RES into the RVLM on sympathetic vasomotor tone by recording $\mathrm{BP}$, heart rate (HR), and renal sympathetic nerve activity (RSNA), and to elucidate the possible central mechanism of its cardiovascular effects.

\section{Materials and methods}

The experiments were performed on 42 male SpragueDawley rats (300 $\pm 5 \mathrm{~g}$, Grade II) obtained from the Experimental Animal Center of Hebei, China. The rats were anesthetized by urethane $(1.0 \mathrm{~g} / \mathrm{kg}$, ip). The trachea was cannulated for ventilation. Body temperature was maintained in the range of $37-38{ }^{\circ} \mathrm{C}$ by a thermostatic bed.

Recording of BP, HR, and RSNA The left femoral artery was cannulated for recording BP by a pressure transducer (MPU-0.5 A; Nihon Kohden, Tokyo, Japan).The left kidney was exposed via a retroperitoneal approach. One branch of the renal sympathetic nerves around the renal vessels was clamped distally to eliminate the afferent activity. The nerve was placed on a bipolar silver electrode for potential recording and immersed in liquid paraffin. The pressure transducer and the bipolar silver electrode were connected with a set of biological polygraph (BL-420E ${ }^{+}$; Chengdu Technology and Market, Chengdu, China) to record BP, HR, and RSNA simultaneously. RSNA was integrated automatically by computer, and the integrated time was $1.6 \mathrm{~s}$. Upon the end of the experiment, the proximal end of the nerve was clamped to get the noise level of RSNA. The basal RSNA was the difference between the integral value of RSNA and the noise level. The difference was recorded as $100 \%$. The data were expressed as the percentage change from basal value.

Exposure of the medulla ventral surface A midline incision was made on the ventral surface of the neck. The trachea and esophagus were transected in the lower neck and reflected rostrally. After retraction of the bilateral longus capitis muscles, the basilar portion of the occipital bone was removed. The ventral surface of the medulla was exposed by incising the dura and the arachnoid and then covered with warm $\left(37^{\circ} \mathrm{C}\right)$ liquid paraffin. Cerebrospinal fluid was constantly drained with a strip of thinly twisted cotton.

Microinjection Anesthetized rats were fixed on a stereotaxic frame (Model IC; Jiangwan, Huaibei, China) in a supine position. A glass micropipette (tip diameter 10-30 $\mu \mathrm{m}$ ) was inserted into the RVLM (stereotaxic coordinates ${ }^{[13]}$ : 1.5-2.0 $\mathrm{mm}$ lateral to midline, $2.6-3.3 \mathrm{~mm}$ posterior to interaural line, and $0.3-0.5 \mathrm{~mm}$ from the ventral surface of medulla oblongata) for the microinjection. The injection filled in the micropipette was delivered into the left RVLM unilaterally by a nanoliter injector (A203XVZ; World Precision, Sarasota, Florida, USA). By regulating the injection mode of the injector, the injection volume $(200 \mathrm{~nL})$ was divided into 8 parts and delivered separately with an interval of $1 \mathrm{~min}(25$ nL per time).

Histological examination To identify the site of microinjection postmortem, $2 \%$ pontamine sky blue was added to the injection. At the completion of the experiments, the animals were deeply anesthetized, and the brainstem was removed and stored in 10\% formalin solution. After 7-10 d, the frozen brain tissue was sectioned in the coronal plane $(40 \mu \mathrm{m})$. Histological verification was carried out with reference to Paxinos and Watson's coordinates ${ }^{[13]}$. The stained area or the depth of the injecting track in the RVLM was examined under a microscope. The results from the animals with injection diffusing out of the RVLM were excluded from statistic data.

Protocols A period of 30 min was allowed for stabilization after the operation. After a stable recording was obtained for more than $5 \mathrm{~min}$, the vehicle was used as the control. After $15 \mathrm{~min}, \mathrm{RES}$ at 20,40 , and $80 \mu \mathrm{mol} / \mathrm{L}(0.2 \mu \mathrm{L})$ was microinjected into the RVLM to examine the effects of different doses of RES on BP, HR, and RSNA. One dose was only tested in each rat.

The effect of tamoxifen (TAM), an estrogen receptor blocking agent, on the response to RES was examined. After the control parameters were obtained, RES $(40 \mu \mathrm{mol} / \mathrm{L}, 0.2 \mu \mathrm{L})$ was microinjected into the RVLM. BP, HR, and RSNA were measured. Approximately $50 \mathrm{~min}$ later, after the parameters recovered to baseline for at least $10 \mathrm{~min}$, TAM $(100 \mu \mathrm{mol} / \mathrm{L}$, $0.2 \mu \mathrm{L}$ ) was microinjected into the RVLM and the parameters were obtained. After $15 \mathrm{~min}$, a microinjection of RES (40 $\mu \mathrm{mol} / \mathrm{L}, 0.2 \mu \mathrm{L}$ ) into the RVLM was carried out again. To determine whether NO was involved, $N^{\mathrm{G}}$-nitro- $L$-arginine methyl ester $(L-N A M E ; 100 \mu \mathrm{mol} / \mathrm{L}, 0.2 \mu \mathrm{L})$ was microinjected into the RVLM to observe the effect of $L$-NAME on that of RES. To determine whether $\mathrm{Ca}^{2+}$ was involved, $\mathrm{BP}, \mathrm{HR}$, and RSNA were examined following the administration of RES $(40 \mu \mathrm{mol} / \mathrm{L}, 0.2 \mu \mathrm{L})$ before and after the microinjection of Bay $\mathrm{K} 8644$ (500 nmol/L, $0.2 \mu \mathrm{L}$ ), an agonist of calcium channels, into the RVLM. To further determine the involvement of protein tyrosine kinase (PTK), one experimental group was treated with sodium orthovanadate $(1 \mathrm{mmol} / \mathrm{L}, 0.2 \mu \mathrm{L})$ for $15 \mathrm{~min}$ before RES was microinjected.

Drugs RES (purity 99\%; Sigma, St Louis, MO, USA) was dissolved in DMSO. TAM (Sigma, USA) and Bay K8644 (Sigma, USA) were dissolved in 99\% ethyl alcohol. The final 
concentration of DMSO or ethyl alcohol in the injection was lower than $0.05 \%$. L-NAME (Sigma, USA) and sodium orthovanadate (Sigma, USA) were dissolved in saline. No changes in BP, HR, and RSNA were observed during the microinjection with DMSO (1:2000) or ethyl alcohol (1:2000).

Statistics All values are presented as mean \pm SEM. The significance of differences between groups was determined by one-way ANOVA and further analyzed by StudentNewman-Kuels test and Dunnett's $t$-test. Differences were considered statistically when $P<0.05$.

\section{Results}

A total of 42 male rats were used in the present study. Figure 1 presents the medullary coronal section summarizing the locations of the RVLM sites for RES microinjection.

A
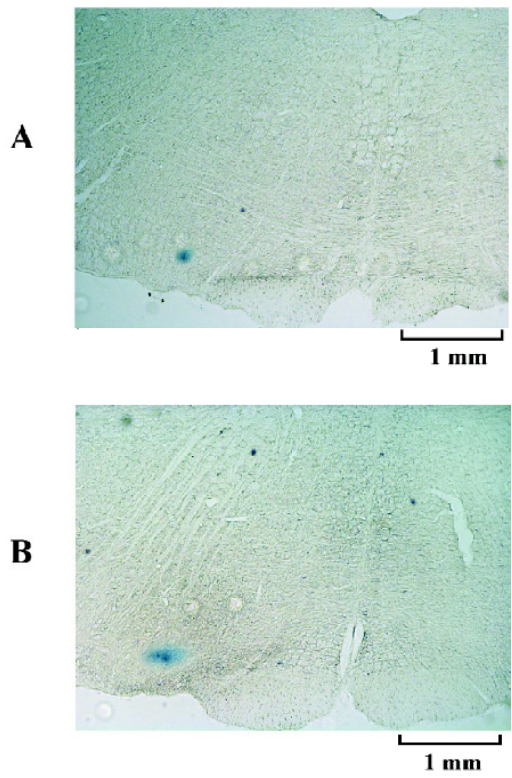

Figure 1. Injection site in the RVLM. (A) $40 \mu \mathrm{mol} / \mathrm{L}(0.2 \mu \mathrm{L}) \mathrm{RES}$; (B) $40 \mu \mathrm{mol} / \mathrm{L}(0.2 \mu \mathrm{L}) \mathrm{RES}+100 \mu \mathrm{mol} / \mathrm{L}(0.2 \mu \mathrm{L}) \mathrm{TAM}+40 \mu \mathrm{mol} / \mathrm{L}$ $(0.2 \mu \mathrm{L}) \mathrm{RES}$.

Effects of RES on BP, HR, and RSNA ( $n=6)$ The microinjection of RES (20, 40, and $80 \mu \mathrm{mol} / \mathrm{L})$ into the RVLM decreased BP, HR, and RSNA in a dose-dependent manner (Figures 2, 3). Following the microinjection of RES $(20 \mu \mathrm{mol} / \mathrm{L})$ into the RVLM, BP, HR, and RSNA were significantly decreased from $103.77 \pm 3.18 \mathrm{mmHg}, 376.83 \pm 7.16 \mathrm{bpm}$, and $100 \% \pm 0 \%$ to $89.48 \pm 3.22 \mathrm{mmHg}(P<0.01), 365.33 \pm 7.01 \mathrm{bpm}$ $(P<0.05)$, and $79.26 \% \pm 0.81 \%(P<0.01)$, respectively. RES (40 $\mu \mathrm{mol} / \mathrm{L})$ decreased BP, HR, and RSNA significantly to $77.23 \pm 4.71 \mathrm{mmHg}(P<0.01$ vs RES $20 \mu \mathrm{mol} /$ Lgroup $), 352.33 \pm 7.80$ bpm $(P<0.05$ vs RES $20 \mu \mathrm{mol} / \mathrm{L}$ group $)$ and $64.66 \% \pm 1.58 \%$

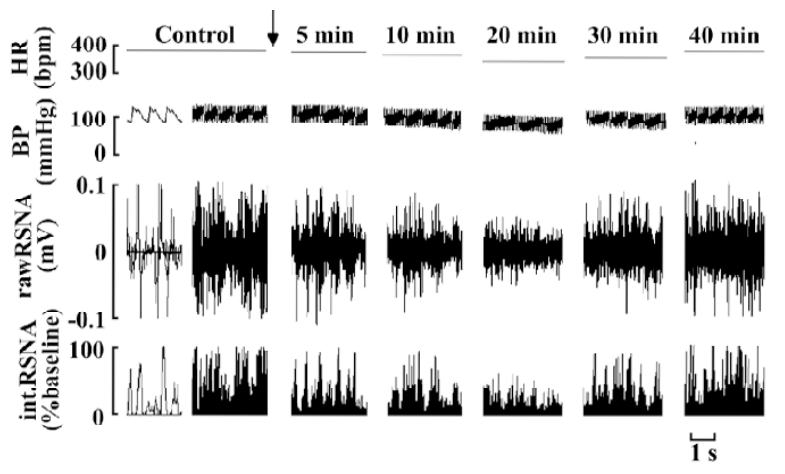

Figure 2. Effects of $80 \mu \mathrm{mol} / \mathrm{L}(0.2 \mu \mathrm{L})$ RES microinjected into the RVLM on HR, BP, and RSNA. $\downarrow$, microinjection of RES.

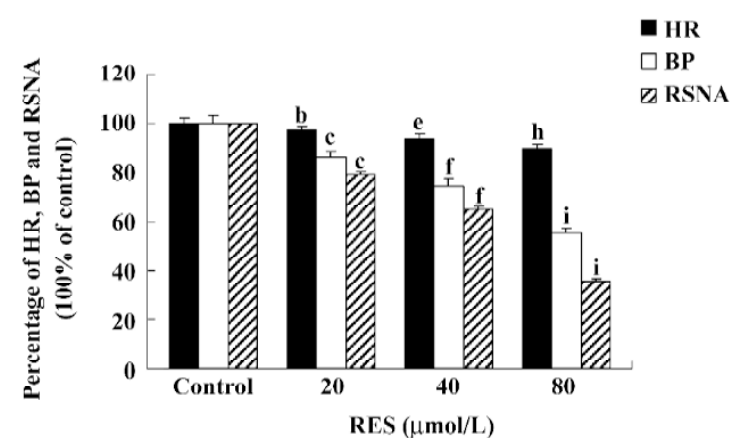

Figure 3. Effect of RES microinjected into the RVLM on BP, HR, and RSNA in anesthetized male rats. $n=6$. Mean \pm SEM. ${ }^{\mathrm{b}} P<0.05$, ${ }^{\mathrm{c}} P<0.01$ vs control; ${ }^{\mathrm{e}} P<0.05,{ }^{\mathrm{f}} P<0.01$ vs $\mathrm{RES}(20 \mu \mathrm{mol} / \mathrm{L})$; ${ }^{\mathrm{h}} P<0.05$, ${ }^{\mathrm{i}} P<0.01$ vs RES $(40 \mu \mathrm{mol} / \mathrm{L})$.

( $P<0.01$ vs RES $20 \mu \mathrm{mol} / \mathrm{L}$ group). After the application of RES ( $80 \mu \mathrm{mol} / \mathrm{L}$ ) into the RVLM, BP, HR, and RSNA were obviously decreased to $57.05 \pm 4.15 \mathrm{mmHg}(P<0.01$ vs RES 40 $\mu \mathrm{mol} / \mathrm{L}$ group $), 337.67 \pm 8.26 \mathrm{bpm}(P<0.05$ vs $\mathrm{RES} 40 \mu \mathrm{mol} / \mathrm{L}$ group), and $35.31 \% \pm 1.16 \%$ ( $P<0.01$ vs RES $40 \mu \mathrm{mol} / \mathrm{L}$ group $)$. The effect started within $10 \mathrm{~min}$, reached its peak within 15-25 min, and lasted for 30-40 min. The vehicle of RES $(0.05 \%$ DMSO in saline) showed no effect on the above parameters $(n=6)$.

RES (40 $\mu \mathrm{mol} / \mathrm{L})$ produced moderate inhibitory effects on BP, HR, and RSNA. The parameters could completely recover within 25-30 min. This concentration was effective and did not produce irreversible damage. It was conducive to observe the response of cardiovascular activities induced by RES to these pretreatments. Therefore, we chose $40 \mu \mathrm{mol} / \mathrm{L}$ RES for the mechanistic evaluation.

Effects of TAM on RES responses ( $\boldsymbol{n}=6)$ In 6 anesthetized rats, the application of RES ( $40 \mu \mathrm{mol} / \mathrm{L})$ into the RVLM decreased BP, HR, and RSNA to $76.50 \%, 93.93 \%$, and $65.32 \%$ of the control, respectively. After recovering from the effects of RES, TAM $(100 \mu \mathrm{mol} / \mathrm{L})$ was administered into 
the RVLM and did not induce any change in the above parameters (from $104.05 \pm 3.75 \mathrm{mmHg}, 370.67 \pm 8.12 \mathrm{bpm}$, and $100 \% \pm 0 \%$ to $103.18 \pm 3.55 \mathrm{mmHg}(P>0.05), 371.83 \pm 7.49 \mathrm{bpm}$ $(P>0.05)$, and $99.73 \% \pm 0.68 \%(P>0.05)$. Fifteen minutes later, RES (40 $\mu \mathrm{mol} / \mathrm{L})$ was remicroinjected, and the same decrease in BP, HR, and RSNA was observed. Therefore, TAM did not influence the effect of RES on the RVLM (Figure 4). The vehicle of TAM $(0.05 \%$ ethyl alcohol in saline) was microinjected in another group and showed no significant effect on $\mathrm{BP}, \mathrm{HR}$, and RSNA $(n=6)$.

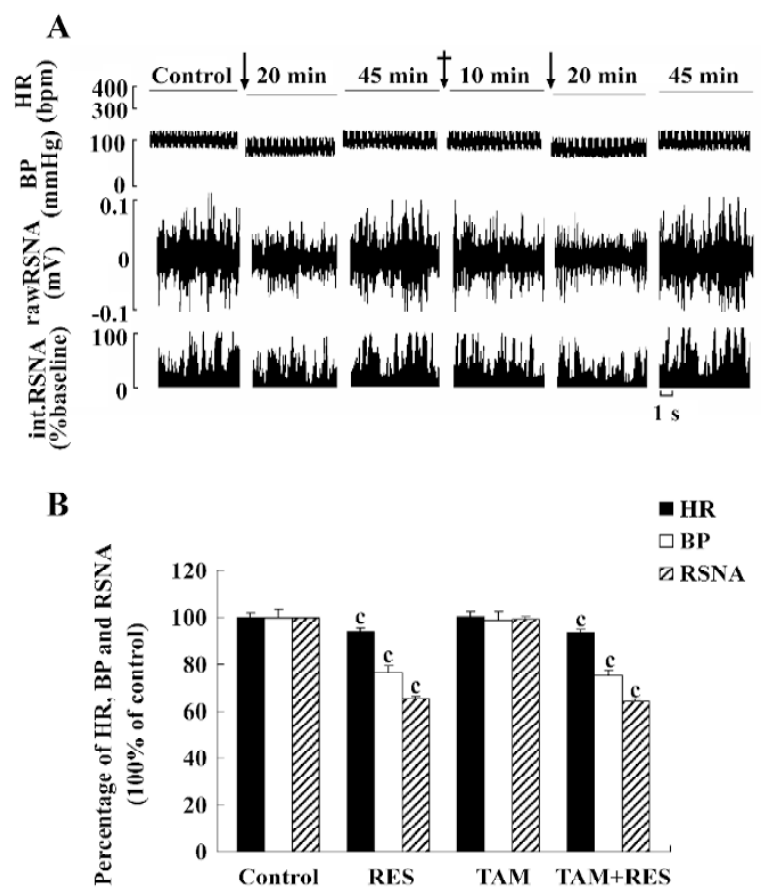

Figure 4. Effect of TAM $(100 \mu \mathrm{mol} / \mathrm{L})$ on the responses of BP, HR, and RSNA to $40 \mu \mathrm{mol} / \mathrm{L}$ RES. (A) original tracing recordings; $\boldsymbol{\downarrow}$, microinjection of RES; I microinjection of TAM. (B) graphic bars, $n=6$. Mean \pm SEM. ${ }^{\mathrm{c}} P<0.01$ vs control.

Effects of $\boldsymbol{L}$-NAME on RES responses ( $\boldsymbol{n}=\mathbf{6})$ RES (40 $\mu \mathrm{mol} / \mathrm{L}$ ) was microinjected into the RVLM. BP, HR, and RSNA decreased. After recovering from the effects of RES, $L$-NAME ( $100 \mu \mathrm{mol} / \mathrm{L})$ was administered into the RVLM and showed no significant effect on the above parameters (from 104.43 \pm 3 . $08 \mathrm{mmHg}, 373.33 \pm 6.03 \mathrm{bpm}$, and $100 \% \pm 0 \%$ of the control to $105.13 \pm 3.81 \mathrm{mmHg}(P>0.05), 375.33 \pm 5.25 \mathrm{bpm}(P>0.05)$, and $100.59 \pm 0.95 \%(P>0.05)$. Fifteen minutes later, RES $(40 \mu \mathrm{mol} / \mathrm{L})$ was remicroinjected and failed to cause any change in BP $(104.08 \pm 3.19 \mathrm{mmHg}, P>0.05 v s$ control $), \mathrm{HR}(372.50 \pm 5.93 \mathrm{bpm}$ $P>0.05 v s$ control), and RSNA $(99.75 \% \pm 1.29 \% P>0.05 v s$ control). The results suggested that the effect of RES in the RVLM might be completely blocked by $L$-NAME (Figure 5).
The vehicle of $L$-NAME (the normal saline) was tested in another group and did not produce any change in the parameters $(n=6)$.

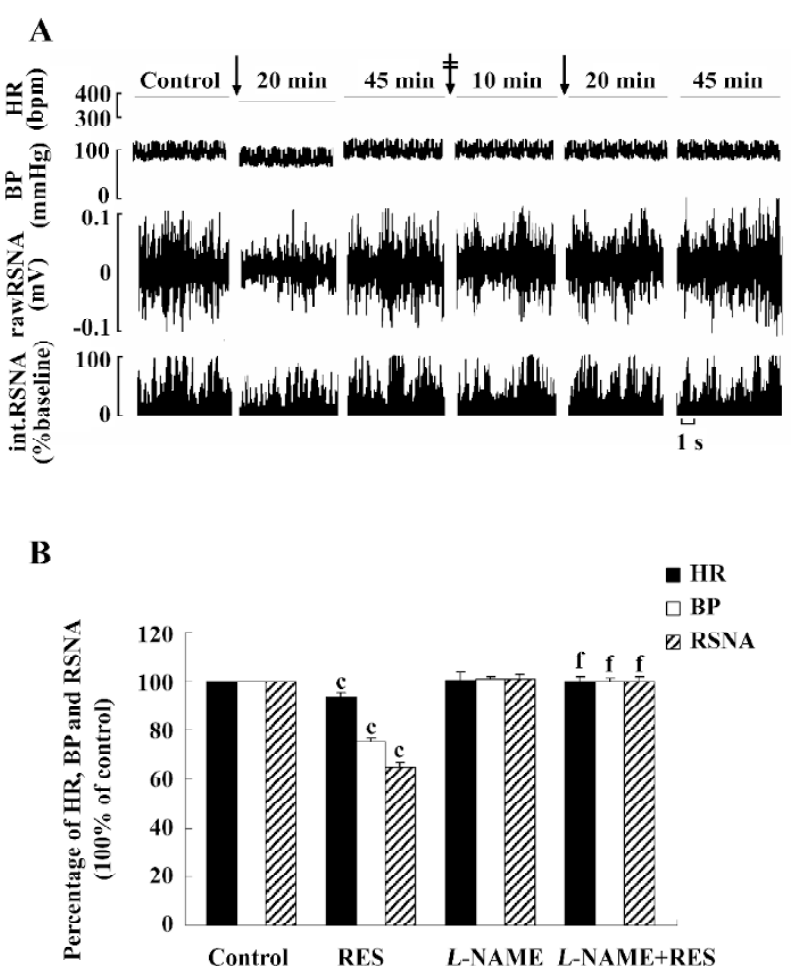

Figure 5. Effect of $100 \mu \mathrm{mol} / \mathrm{L} L-\mathrm{NAME}$ on the responses of BP, $\mathrm{HR}$, and RSNA to $40 \mu \mathrm{mol} / \mathrm{L}$ RES. (A) original tracing recordings; $\downarrow$, microinjection of RES; $\mathbf{\ddagger}$, microinjection of L-NAME. (B) graphic bars, $n=6$. Mean \pm SEM. ${ }^{\mathrm{c}} P<0.01$ vs control, ${ }^{\mathrm{f}} P<0.01$ vs $\mathrm{RES}(40 \mu \mathrm{mol} / \mathrm{L})$.

Effect of Bay K8644 on RES responses ( $\boldsymbol{n}=6)$ The effects of RES (40 $\mu \mathrm{mol} / \mathrm{L})$ were observed first, and BP, HR, and RSNA decreased to $76.19 \%, 93.98 \%$, and $67.33 \%$ of the control, respectively. After recovering from the effects of RES, Bay K8644 (500 nmol/L) was microinjected into the RVLM, and the parameters showed no significant change [from $102.73 \pm 2.56 \mathrm{mmHg}, 365.17 \pm 6.18 \mathrm{bpm}$, and $100 \% \pm 0 \%$ of the control to $103.25 \pm 2.97 \mathrm{mmHg}(P>0.05), 368.17 \pm 7.27$ $\operatorname{bpm}(P>0.05)$, and $101.20 \pm 1.08 \%(P>0.05)]$. Fifteen minutes later, RES (40 $\mu \mathrm{mol} / \mathrm{L})$ was remicroinjected and failed to cause any change in BP, HR, and RSNA [101.67 $\pm 2.93 \mathrm{mmHg}$ ( $P>0.05$ vs control), $363.83 \pm 6.42 \mathrm{bpm}(P>0.05$ vs control)], and $99.35 \% \pm 0.85 \%$ ( $P>0.05 v s$ control $)$ ]. Therefore Bay K8644 could completely abolish the action of RES (Figure 6). The vehicle of Bay K8644 (0.05\% ethyl alcohol in saline) showed no significant effect on BP, HR, and RSNA ( $n=6)$.

Effects of sodium orthovanadate on RES responses $(n=6)$ RES ( $40 \mu \mathrm{mol} / \mathrm{L}$ ) was microinjected into the RVLM. BP, HR, 

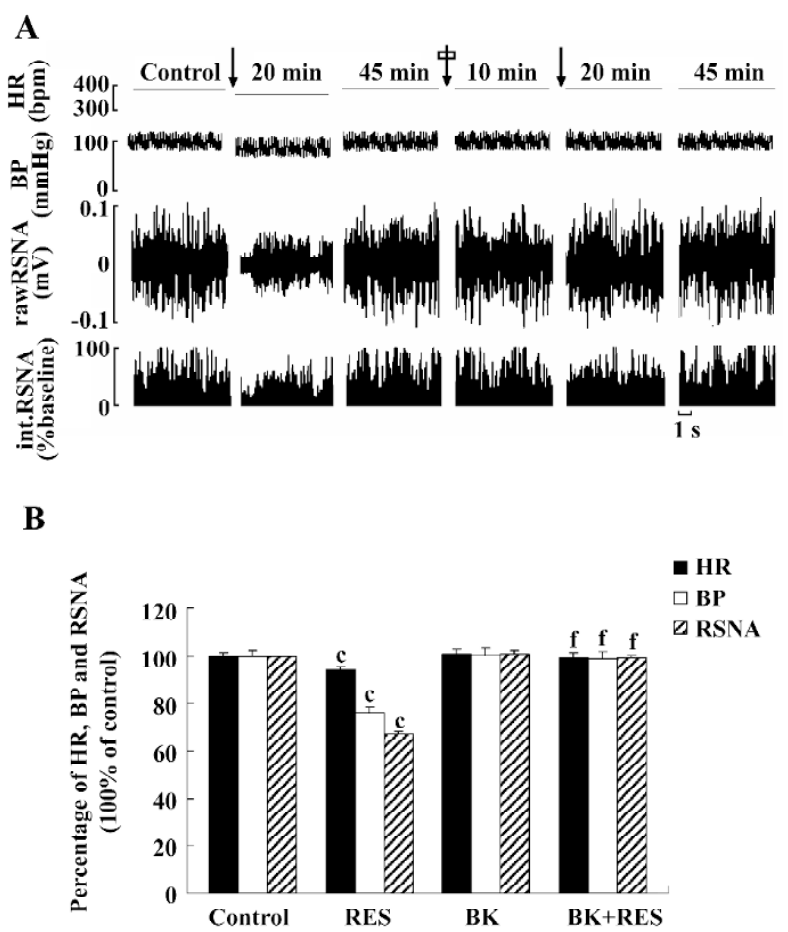

Figure 6. Effect of $500 \mathrm{nmol} / \mathrm{L}$ Bay K8644 on the responses of BP, $\mathrm{HR}$, and RSNA to $40 \mu \mathrm{mol} / \mathrm{L}$ RES. (A) original tracing recordings; $\downarrow$, microinjection of RES; 中, microinjection of Bay K8644. (B) graphic bars, $n=6$. Mean \pm SEM. ${ }^{\mathrm{c}} P<0.01$ vs control, ${ }^{\mathrm{f}} P<0.01$ vs RES (40 $\mu \mathrm{mol} / \mathrm{L})$.

and RSNA decreased to $75.13 \%, 93.19 \%$, and $64.37 \%$ of the control, respectively. After recovering from the effects of RES, sodium orthovanadate $(1 \mathrm{mmol} / \mathrm{L})$ was administered into the RVLM and did not affect the parameters significantly [from $103.85 \pm 3.45 \mathrm{mmHg}, 372.17 \pm 6.37 \mathrm{bpm}$, and $100 \% \pm 0 \%$ of the control to $102.40 \pm 3.32 \mathrm{mmHg}(P>0.05), 370.17 \pm 6.70 \mathrm{bpm}$ $(P>0.05)$, and $99.78 \% \pm 1.18 \%(P>0.05)]$. Fifteen minutes later, RES (40 $\mu \mathrm{mol} / \mathrm{L})$ was remicroinjected. BP, HR, and RSNA decreased to $85.17 \%, 96.82 \%$, and $78.62 \%$ of the control, respectively. The results suggested that sodium orthovanadate could partially attenuate the inhibitory effects of RES on the RVLM (Figure 7). The vehicle of sodium orthovanadate (the normal saline) did not produce any change in the parameters $(n=6)$.

The microinjection vehicle of RES (600 nL) into the RVLM had no significant effect on BP, HR, and RSNA $(n=6)$. Therefore, changes caused by mechanical damage could be ruled out.

\section{Discussion}

The present study demonstrates that RES inhibits BP, $\mathrm{HR}$, and RSNA in a concentration-dependent manner. It is well established that the sympathetic-related neurons in the
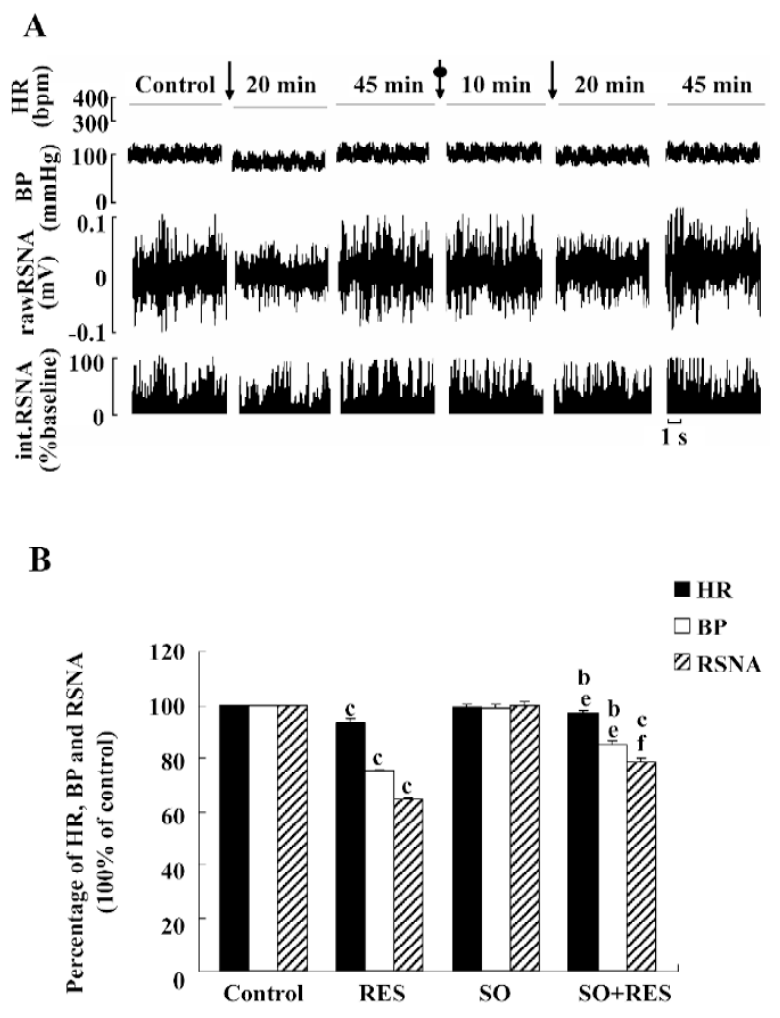

Figure 7. Effect of $1 \mathrm{mmol} / \mathrm{L}$ sodium orthovanadate ( $\mathrm{SO}$ ) on the responses of $\mathrm{BP}, \mathrm{HR}$, and RSNA to $40 \mu \mathrm{mol} / \mathrm{L}$ RES. (A) original tracing recordings; $\$$, microinjection of RES; $\downarrow$, microinjection of sodium orthovanadate. (B) graphic bars, $n=6$. Mean \pm SEM. ${ }^{\mathrm{b}} P<0.05$, ${ }^{\mathrm{c}} P<0.01$ vs control. ${ }^{\mathrm{e}} P<0.05,{ }^{\mathrm{f}} P<0.01$ vs $\mathrm{RES}(40 \mu \mathrm{mol} / \mathrm{L})$.

RVLM innervate cholinergic preganglionic sympathetic neurons in the spinal cord, and stimulation of the RVLM increases arterial BP and sympathetic outflow ${ }^{[14]}$. The RVLM can continue to drive sympathetic nerve activity to regulate arterial BP in the chronic absence of baroreceptor input in baroreceptor-denervated rats ${ }^{[15]}$. It is a key region for the control of sympathetic drive to the periphery. The inhibitory effect of RES on the RVLM means that RES can decrease the sympathetic outflow of RVLM, resulting in a decrease of arterial BP. RES may show potential clinical value in the treatment of hypertension and other related cardiovascular diseases as an inhibitor of the sympathetic nerve center.

RES is a kind of phytoestrogen and can exert genomic and non-genomic actions on target tissues via estrogen receptors $^{[16]}$. The $\alpha$ and $\beta$ forms of estrogen receptors have been cloned from human and rats, which have been identified in a wide range of tissues, including the cardiovascular system and central nervous system. Multiple brain regions concerning central cardiovascular regulation, including nu- 
clei tractus solitarii, ventrolateral medulla, and area postrema, contain both forms of estrogen receptors ${ }^{[17]}$. The anti-estrogen TAM, which acts by binding to estrogen receptors and has been shown to prevent classic estrogen effects, did not influence the inhibitory effect of RES on the RVLM neurons. Thus the observed effect of RES in our experiments might act in a rapid, non-genomic mechanism and might not be attributed to estrogen receptor mediation.

$\mathrm{NO}$ is a novel messenger in the central nervous system and has an important influence on the RVLM and sympathetic nerve activity ${ }^{[18]}$, Chan et al found that NO synthase (NOS) I, II, and III were expressed in the RVLM ${ }^{[19]}$. The increase of NO production caused by the overexpression of NOS III in the bilateral RVLM could decrease BP, HR, and RSNA ${ }^{[20]}$. Kiziltepe's study shows that RES can upregulate NO in the spinal cord ${ }^{[21]}$. Furthermore, our previous work has demonstrated that RES can inhibit the electrical activity of subfornical organs ${ }^{[22]}$ and hippocampal CA1 area $^{[23]}$ neurons induced by $L-N A M E$ via locally-produced NO. In the present study, pretreatment with $L$-NAME, a non-selective inhibitor of NOS, completely blocked the action of RES, thus suggesting that RES exerts its inhibitory effects on the RVLM via increasing the synthesis of NO.

It is well known that $\mathrm{NO}$ can inhibit the $\mathrm{Ca}^{2+}$ influx in neurons ${ }^{[24]}$. We used Bay K8644, an agonist of calcium channels, to further determine the involvement of $\mathrm{Ca}^{2+}$. The fact that Bay K8644 completely blocks the inhibitory effect of RES on the RVLM in our study strongly suggests that the inhibitory effects of RES might be due to the blockade of calcium influx. This result is consistent with that of our previous study, which shows that RES can affect the calcium channel and significantly inhibit $\mathrm{Ca}^{2+}$ influx into subfornical organs ${ }^{[22]}$ and hippocampal CA1 area ${ }^{[23]}$ neurons. Gong's study also shows that RES can inhibit intracellular free $\mathrm{Ca}^{2+}$ concentration in rat primary neuron cultures ${ }^{[25]}$. Considering that Bay K8644 is a selective L-type voltagegated calcium channel agonist, this inhibitory effect might be mainly due to the blockade of the L-type voltage-gated calcium channel. Therefore, it may be proposed that RES might increase the production of $\mathrm{NO}$ and subsequently inhibit $\mathrm{Ca}^{2+}$ influx through the L-type voltage-gated calcium channel.

RES has been proven to be an inhibitor of PTK ${ }^{[26]}$. PTK activity is a major signaling mechanism in regulating cell growth, division, metabolism, and ion channel conductance ${ }^{[27]}$. Evidence has been presented to suggest that the intracellular $\mathrm{Ca}^{2+}$ through the L-type voltage-gated calcium channel can activate PTK in neurons ${ }^{[28-30]}$. Sodium orthovanadate, an inhibitor of tyrosine phosphatase, can enhance protein tyrosine phosphorylation. Our present study shows that sodium orthovanadate partially abolishes the inhibitory effects of RES on BP, HR, and RSNA, suggesting that the PTK pathway is involved. Taken together, our data and previous findings, infer that RES increases NO synthesis, attenuates $\mathrm{Ca}^{2+}$ influx through the L-type voltage-gated calcium channel, and then inhibits PTK in the RVLM neurons.

In summary, the present study has revealed that RES inhibits the RVLM and decreases sympathetic vasomotor tone. It is also possible that the altered excitability of the RVLM neurons induced by the NOS inhibitor, calcium channel agonist, or PTK inhibitor also desensitizes the RVLM neuronal response to RES and then reduces the RES effects.

\section{Author contributions}

Yu-ming WU designed research and revised paper; Huijuan MA performed research, analyzed data, and wrote the paper; Ya-kun CAO performed research and analyzed data; Yi-Xian Liu and Ru WANG analyzed data.

\section{References}

1 Novakovic A, Gojkovic-Bukarica L, Peric M, Nezic D, Djukanovic B, Markovic-Lipkovski J, et al. The mechanism of endothelium-independent relaxation induced by the wine polyphenol resveratrol in human internal mammary artery. J Pharmacol Sci 2006; 101: 85-90.

2 Yu C, Shin YG, Chow A. Human, rat, and mouse metabolism of resveratrol. Pharm Res 2002; 12: 1907-14.

3 Burns J, Yokota T, Ashihara H, Lean ME, Crozier A. Plant foods and herbal sources of resveratrol. J Agric Food Chem 2002; 50: 3337-40.

4 Sato M, Ray PS, Maulik G, Maulik N, Engelman RM, Bertelli AA, et al. Myocardial protection with red wine extract. J Cardiovasc Pharmacol 2000; 35: 263-8.

5 Pendurthi UR, Williams JT, Rao LV. Resveratrol, a polyphenolic compound found in wine, inhibits tissue factor expression in vascular cells: a possible mechanism for the cardiovascular benefits associated with moderate consumption of wine. Arterioscler Thromb Vasc Biol 1999; 19: 419-26.

6 Das DK, Maulik N. Resveratrol in cardioprotection: a therapeutic promise of alternative medicine. Mol Interv 2006; 6: 36-47.

7 Hung LM, Chen JK, Huang SS, Lee RS, Su MJ. Cardioprotective effect of resveratrol, a natural antioxidant derived from grapes. Cardiovasc Res 2000; 47: 549-55.

8 Dong HH, Ren HL. New progression in the study of protective properties of resveratrol in anticardiovascular disease. Bratisl Lek Listy 2004; 105: 225-9.

9 Li HF, Wang LD, Tian ZF, Li W, Zheng TZ. Effects of phytoestrogens resveratrol and phloretin on contractile response of aortic strips in rabbits. Chin J Pharmacol Toxicol 2006; 20: 26-32.

10 Providencia R. Cardiovascular protection from alcoholic drinks: scientific basis of the French. Paradox. Rev Port Cardiol 2006; 
25: $1043-58$

11 Terui N, Saeki Y, Kumada M. Barosensory neurons in the ventrolateral medulla in rabbits and their responses to various afferent inputs from peripheral and central sources. Jan J Physiol 1986; 36: 1141-64.

12 Verberne AJ, Srornetta RL, Guyenet PG. Properties of C1 and other ventrolateral medullary neurons with hypothalamic projections in the rat. J Physiol (Lond) 1999; 517: 477-94.

13 Paxinos G, Watson C. The rat brain in stereotaxic coordinates. 4th ed. San Diego: Academic Press; 1999.

14 Reis DJ, Granata AR, Joh TH, Ross CA, Ruggiero DA, Park DH. Brain stem catecholamine mechanisms in tonic and reflex control of blood pressure. Hypertension 1984; 6: 7-15.

15 Schreihofer AM, Ito S, Sved AF. Brain stem control of arterial pressure in chronic arterial baroreceptor-denervated rats. Am J Physiol Regul Integr Comp Physiol 2005; 289: R1746-R1755.

16 Henry LA, Witt DM. Resveratrol: phytoestrogen effects on reproductive physiology and behavior in female rats. Horm Behav 2002; 41: 220-8

17 Shughrue PJ, Lane MV, Merchenthaler I. Comparative distribution of estrogen receptor alpha and beta mRNA in the rat central nervous system. J Comp Neurol 1997; 388: 507-25

18 Yang LM, He RR. Effects of microinjection of $L$-NNA and SNP into ventrolateral medulla on blood pressure, heart rate and renal sympathetic nerve activity in rats. Acta Physiol Sin 1996; 48: 368-76.

19 Chan JY, Chan SH, Chang AY. Differential contributions of NOS isoforms in the rostral ventrolateral medulla to cardiovascular responses associated with mevinphos intoxication in the rat. Neuropharmacology 2004; 46: 1184-94.

20 Kishi T, Hirooka Y, Sakai K, Shigematsu H, Shimokawa H, Takeshita A. Overexpression of eNOS in the RVLM causes hypotension and bradycardia via GABA release. Hypertension 2001, 28: 896-901

21 Kiziltepe U, Turan NN, Han U, Ulus AT, Akar F. Resveratrol, a red wine polyphenol, protects spinal cord from ischemiareperfusion injury. J Vasc Surg 2004; 40: 138-45.

22 Li M, Wang QS, Chen Y, Wang ZM, Liu Z, Guo SM. Resveratrol inhibits the electrical activity of subfornical organ neurons in rat. Acta Physiol Sin 2005; 57: 523-8.

23 Li M, Wang QS, Chen Y, Wang ZM, Liu Z, Guo SM. Resveratrol inhibits neuronal discharges in rat hippocampal CA1 area. Acta Physiol Sin 2005; 57: 355-60.

24 Chaban VV, McRoberts JA, Ennes HS, Mayer EA. Nitric oxide synthase inhibitors enhance mechanosensitive $\mathrm{Ca}^{2+}$ influx in cultured dorsal root ganglion neurons. Brain Res 2001; 903: 74-85.

25 Gong QH, Wang Q, Shi JS, Huang XN, Liu Q, Ma H. Inhibition of caspases and intracellular free $\mathrm{Ca}^{2+}$ concentrations are involved in resveratrol protection against apoptosis in rat primary neuron cultures. Acta Pharmacol Sin 2007; 28: 1724-30.

26 Feng YH, Zhou WL, Wu QL, Li XY, Zhao WM, Zou JP. Low dose of resveratrol enhanced immune response of mice. Acta Pharmacol Sin 2002; 23: 893-7.

27 Gao Z, Lau CP, Wong TM, Li GR. Protein tyrosine kinase dependent modulation of voltage-dependent potassium channels by genistein in rat cardiac ventricular myocytes. Cell Signal 2004; 16: 333-41.

28 Pei L, Li Y, Yan JZ, Zhang GY, Cui ZC, Zhu ZM. Changes and mechanisms of protein-tyrosine kinase and protein tyrosine phosphatase activities after brain ischemia/reperfusion. Acta Phamacol Sin 2000; 21: 715-20.

29 Pei L, Li Y, Zhang GY, Cui ZC, Zhu ZM. Mechanisms of regulation of tyrosine phosphorylation of NMDA receptor subunit $2 \mathrm{~B}$ after cerebral ischemia/ reperfusion. Acta Pharmacol Sin 2000; 21: 695-700.

30 Hou XY, Zhang GY, Yan JZ, Liu Y. Activation of NMDA receptor and L-type voltage-gated calcium channels mediates enhanced formation of Fyn-PSD95-NR2A complex after transient brain ischemia. Brain Res 2002; 955: 123-32. 